\title{
THE SPOKEN LANGUAGE PROGRAM OF THE ARMY JAPANESE LANGUAGE SCHOOL AT THE UNIVERSITY OF MICHIGAN ${ }^{1}$
}

\author{
JoSEPH K. YaMAGIWA \\ University of Michigan
}

$\mathbf{T}^{\mathrm{s}}$

HE BASIC MATERIALS AND METHODS underlying the spoken lan-

guage programs given to the students of the Army Japanese Language School, the ASTP unit, and the Civil Affairs Training School at the University of Michigan were developed in 1943 and the early part of 1944 . The materials used in the programs were changed from time to time in accordance with changing conditions, the chief of which was the gradual shift from training for combat intelligence to training for the work of occupation. The following is a description of the spoken language program given to Classes $\mathrm{V}$, VI, and VII of the Army Japanese Language School. These were the classes that received training both for combat intelligence and for occupation.

By May, 1944, when Class IV of the Army Japanese Language School had arrived in Ann Arbor, the staff had acquired enough experience with methods to adopt the oral-aural approach for beginners in the study of Japanese. The oral-aural approach means devoting the first five or six weeks to the spoken language without reference to written materials. The students memorize the spoken models with no attempt at grammatical analysis. They mimic in unison the instructor's pronunciation of the lesson materials at the beginning of each recitation. The advantages of such a procedure are that the students imitate a good model, the teacher instantly corrects pronunciation, and the subject matter is covered just prior to discussion. In contrast with this procedure, the usual one of individual reading and correction is time-consuming and does not affect, completely, the students who are not reading. In addition, the oralaural approach means that nearly all of the work in the classroom

1 I should like to record here my deep sense of gratitude to Alva L. Davis, David W. Reed, and J. W. Downer of the staff of Language Learning for their very real efforts in reshaping this portion of a report that was originally submitted to certain Army authorities.-J.K.Y. 
is carried on in the language which is being taught. In the Japanese School this meant that the students were flooded with the sounds of the language for four hours a day.

In the Japanese School, the materials initially used were those found in a booklet entitled Introduction to Spoken Japanese, ${ }^{2}$ in which greetings, questions, and phrases are given in a series of short dialogues such as might occur in everyday life. Thus the students were given the ordinary directions necessary in conducting work in the classroom and phrases required in the home, in calling on someone else, in buying things, etc. Instead of explaining each phrase or sentence grammatically and using English in the explanation, the instructors asked the students to mimic the model pronunciations and to memorize each phrase or sentence. The students came out of this initial training with a clear concept of Japanese pronunciation. More important, they acquired a fund of phrases and sentences useful in the very elementary business of getting food, clothing, shelter, and transportation. When the time finally came for them to study the characters used in writing, in large measure they merely attached the writings to the pronunciations and meanings that they already knew.

The adoption of the oral-aural approach seemed justified in the results achieved. Conclusive figures based on the testing of large groups of students cannot be given, but the following data concerning civilian classes in Japanese at the university seem pertinent. A civilian class was started with the spoken language in the fall of 1943. During the entire first month the class concentrated on the spoken language and did nothing with the written. At the end of one semester, the class had covered 193 pages of reading material as against 147 for the previous class and had been exposed to 402 kanzi (Chinese characters used in writing Japanese) as against 296 for the previous class. The students in both classes were of only average ability. The fall class covered $36 \%$ more characters and read $31 \%$ more pages. Also, more work was done with the spoken language. The percentages of increase perhaps cannot be maintained, but the figures seem convincing enough to justify the adoption of the oral-

${ }^{2}$ Introduction to Spoken Japanese (multigraphed edition), Japanese Language School, University of Michigan, Ann Arbor, 1945. 
aural approach in dealing with beginning students of a second language.

This approach, moreover, would be valuable for students who have already had previous training in the language, but who have not been exposed to it for some time. Such students need at least two or three weeks of concentration on the spoken language before they arrive at any previously attained point of proficiency.

The emphasis on the use of spoken Japanese in the first exposure of students to that language did not mean that lectures and discussions in English were entirely ruled out. In a three or four week period, during which the Introduction to Spoken Japanese was the only text used, lectures were given at the rate of one a week. These lectures were based on Part I of my Modern Conversational Japa$n e s e,{ }^{3}$ in which the pronunciation of Japanese words is discussed. But even in the lectures, the students participated en masse in pronunciation drill using the illustrative Japanese words found both in Modern Conversational Japanese and in certain sheets entitled Japanese Pronunciation Drill. ${ }^{4}$

The oral-aural approach, with all that it means-the fixing of pronunciation habits, the memorizing of phrases and sentences that are useful in everyday life, and the mimicking in unison of the pronunciation of instructors-is followed by a second stage. In this stage ample recognition is given to the belief that the best drill should be based on an understanding of the structure of the language that is being studied.

In the first stage, the student may learn to say the Japanese equivalents for "How much is the fare?" without learning to say "How much is the bread?" In learning the series of Japanese sounds for "How much is the fare?" he does not necessarily discover what the Japanese word for fare is. Not knowing this, he does not know where in the Japanese sentence he may substitute the word bread for the word fare. Or, he may discover enough of the language to learn how the verb $b e$ is expressed in one situation, without learning at the same time that several ways of expressing $b e$ are found in

${ }^{3}$ J. K. Yamagiwa, Modern Conversational Japanese, McGraw-Hill, New York and London, 1942.

4 Japanese Pronunciation Drill (multigraphed edition), Japanese Language School, University of Michigan, Ann Arbor, 1945. 
Japanese. Thus, it seems clear that better usage comes from better understanding, and that lectures are needed in which the Japanese language is gradually analyzed.

In the Japanese School, Parts II and III of Modern Conversational Japanese were used as the basic text for the lectures. But even more important was the first part of a series known as Japanese Speech Patterns. ${ }^{5}$ These Speech Patterns successively illustrate with a multitude of examples the same points raised in Parts II and III of Modern Conversational Japanese, and were introduced into the schedule in the third or fourth week of instruction. In using Speech Patterns, the students were exposed each hour to a whole series of sentences that illustrate the same grammatical pattern; thus in one hour they might learn sentences of the type "I am a student," "You are a soldier," and "He is a doctor," and in the second hour sentences of the type "I am reading a book," "You are writing a letter," and "She is buying a book." The students learn that am, are, and is, and am reading, are writing, and is buying are constructed in the same way in Japanese. The order in which these patterns of usage are learned is generally from the more simple and frequent to the more complex; the least frequently used grammatical devices are covered at the end of this phase of the work.

A cardinal rule of the Japanese School was that in the classroom only Japanese was to be used. The theory that lies behind the adoption of this rule runs as follows: the students are forced to organize their ideas and to state them as native speakers would, to show independence and initiative in expressing themselves in Japanese, and to recall vocabulary and grammar constructions to which they have previously been exposed. Using English to any extent whatsoever breaks the concentration of a class conducted in Japanese and shortens the total time in which the students are speaking Japanese. Various suggestions were made in order to supplement and to clarify the rule that only Japanese was to be used. These suggestions were needed because inexperienced teachers were inclined to ask, "How

- Japanese Speech Patterns, part i, 1945; part ii, 1945; part iii, reentitled Conversations in Japanese, 1945; part iv, 1944; and part v, 1944, all in multigraphed editions, Japanese Language School, University of Michigan, Ann Arbor. 
can Japanese alone be used? How can we possibly avoid using English?" The suggestions had to do primarily with the conduct of the "speech pattern" hours when one of the chief aims was to get students to control successively more difficult constructions.

At the start of the "speech pattern" hours, the students were asked to mimic the sentences in Speech Patterns as spoken by the instructor. Corresponding sentences in Modern Conversational Japanese were also mimicked. This was followed by one or more of the following procedures:

a. The placing of the sentences in Speech Patterns in a story or anecdote was followed by the asking of a series of questions probing into the degree of comprehension by the students.

b. Dialogues among the students or between instructor and student were started with the sentences brought into the dialogue.

c. Particular sentences were converted into questions so phrased that the response would bring forth a repetition of the same forms.

d. If the various imperative forms were to be taught, the students were asked to use or to follow a succession of commands or requests.

e. Forms which had already been taught were brought into the discussion wherever they were related to the new materials.

Defining a Japanese word with an English word was frowned upon except in the case of the more abstract words which require long and elaborate explanations. Whenever there was doubt as to whether a student had comprehended the meaning of a noun, questions were asked as to the location, operation, composition, and description of the thing named by the noun. Verbs and descriptive words were tested by asking questions about the things with which these forms are most closely connected. Anecdotes were sometimes used to explain abstractions. English was used only as a last resort.

In trying further to fix the items to be learned, the instructors had the students form Japanese sentences using the particular patterns and vocabulary items. Here a premium was placed on ingenuity of statement and on variety of construction. This might be further followed by questioning on the part of teachers and students, 
so that a semblance of actual conversation would be attained. Connected discourse bringing in additional uses of the forms was often undertaken near the end of the hour, by both the students and the teacher.

The successful correction of pronunciation was a major teaching problem. The instructors themselves were naturally affected by the speech forms current in various dialect areas; and keen observation of differences in pronunciation, beyond that which told an instructor that a student was speaking with a "foreign accent," was a matter requiring considerable perceptiveness and training. The attempt was to teach the standard pronunciation of Tokyo, that is, the pronunciation of persons who belong to the middle class or higher. But only twenty per cent of the instructors spoke a language that was close to the Tokyo standard; fully fifty per cent spoke a dialect that departed considerably from that of Tokyo. Most of the dialect speakers used the language of the Kansai area, which lies west of Kyoto. The members of the staff who were born in Japan (isseis) came largely from areas where dialects are spoken. Those born in the United States (niseis) had naturally been exposed to other dialects. Many of the niseis were sent to Japan for schooling, often to provincial schools near the original homes of their fathers and mothers. Not all of them were able to stay for extended periods of time in the Tokyo speech area. In correcting the pronunciation of students it was found that the instructors could be trusted to correct certain errors but not others. Those errors that could easily be corrected, without confusing the students, were errors no matter which dialect was taken as the norm. It was assumed that at those points where the instructors' dialects agreed, the corrections would be uniform. Those elements of Japanese speech which the instructors could thus freely correct were as follows:

a. Pronouncing the Japanese $r$ incorrectly. Most students found that the $r$ (a "single-tap" $r$ ) was the most difficult single sound to control, but achieved complete control in a month or so.

b. Making long vowels short and short vowels long. (Some deviations are current in certain dialect areas in Japan.)

c. Making single consonants double and double consonants single. 
d. Not nasalizing medial $g$. The nasalization, however, is not usually necessary for understanding, and in large areas of Japan the $g$ is consistently "hard." If the medial nasalized $g$ was not achieved, the students were allowed to pronounce the medial $g$ "hard." Wrong pronunciation of medial $g$, that is, emphasizing the nasality and pronouncing it like $n$ plus $g$ is non-Japanese, and was corrected. The students in general required a certain amount of training before they were able to recognize medial $g$ : they tended to confuse the sound with $n$ and to write transcriptions like $-n a,-n i,-n e$, and $-n o$ for syllables in which medial $g$ occurred.

e. Alternating the accent in successive syllables. The students tended as in English to give recurrent pitch or stress accents to syllables at approximately even time intervals and this seemed to result in accents on alternate syllables.

In order to solve the problem of correcting pronunciation, further suggestions were made:

a. If the instructors were asked what the pitch pattern of a Japanese word was, they were counseled to tell the students what they themselves would say, not what they thought was right or wrong and not what they thought the pitch pattern of Tokyo was.

b. The instructors in beginning sections were asked to check each other's pronunciation and to arrive at some kind of uniformity before they went to class.

c. The instructors were also asked to send students who had special pronunciation difficulties to Dr. Hide Shohara, a member of the staff who had had considerable experience in speech correction and who guided the students individually during the supervised study hours. The Mirrophone often proved helpful.

d. An attitude of greater consciousness of pronunciation matters was encouraged.

As a matter of policy, an attempt was made to place instructors who spoke the Tokyo dialect in the beginning sections and to have at least one good speaker of the Tokyo standard in each of the more advanced groups. Variety was accepted in the higher sections, and there was also virtue in this, since in the field or in Japan, the trainees would necessarily speak with a variety of dialect speakers. 
The third and final stage of work in the spoken language, which in part overlapped the second, began in the third month of instruction and consisted of a series of "Speech Hours." Here the chief objective was the development of fluency in speech. The material upon which the work was based now possessed greater content value; it was no longer in the form of isolated sentences ${ }^{6}$ but always in the shape of connected discourse. The grammar, it was assumed, had now been learned; the grammar in the new materials was not organized pedagogically.

A basis for conversation was established. The students no longer were concerned with elementary matters; they now received training in the subject-matters, military or administrative, that would be their chief concern as they went into the field. The attempt was to strive for ready and easy use of speech, that is, of vocabulary and grammar items deftly used in the expression of ideas and feelings in several subject areas.

Even before the series of texts known as Speech Patterns was finished, a spoken language program was initiated which used the reading lesson of the day as a basis for conversation. After reading their lessons in the morning, the students returned in the afternoon and discussed a topic that was suggested by the lesson. The following are examples of the topics used on certain lessons in the second volume of the readers that were used: ${ }^{7}$

$\begin{array}{ll}\text { Tōkyō de mitai mono (The things I } & \text { Lesson } 1 \text { (Tōkyō) } \\ \text { want to see in Tokyo) } & \text { Lesson } 5 \text { (Sabaku no } \\ \text { Amerika no sabaku } & \text { hanasi) } \\ \text { (Deserts of America) } & \text { Lessons 6, 12,19 } \\ \text { Nihon no otogibanasi (Japanese fairy } & \text { (Fairy tales) } \\ \text { tales) } & \text { Lesson } 9 \text { (Hagoromo) } \\ \text { Bakemono no hanasi (Ghost stories) } & \text { Lesson 29 (Kanzi) } \\ \text { Kanzi kitigai (Kanzi-crazy-an en- } & \\ \text { thusiast in learning Chinese } & \\ \text { characters) } & \end{array}$

${ }^{6}$ Actually, the materials in Conversations in Japanese (part iii of the Japanese Speech Patterns), is in dialogue or conversational form.

${ }^{7}$ Naoe Naganuma, Hyozyun Nihongo Tokuhon (Standard Japanese Readers), lithoprinted edition, Ann Arbor, v. d. This series of readers runs to seven volumes. Only volumes I-IV were used in the Japanese Language School. 
Using the reading lessons as the basis for the Speech Hours meant that students received considerable speech training by the time they covered the fifth and concluding part of Speech Patterns. When the Speech Hours based on the reading lessons and the five sets of Speech Patterns were finished, and this took as long as eight months for beginners, they had learned the fundamentals of standard, honorific, humble, and informal speech. They were now ready for a series of specialized materials, all cast in dialogue or conversational form, which projected them into the future, so that they could consistently picture themselves using Japanese in both informal and formal situations, talking easily in everyday conversation at first, then proceeding to more technical uses of the language. The emphasis gradually came to be centered on military and administrative situations. The starting point was almost always a dialogue or conversation, that is, an active language situation in which two or more persons are talking with each other. There was much liveliness and actuality in the dialogues; a humdrum statement of facts was avoided.

The first materials in this category were the Informal Conversations in Japanese, Including Plays and Movie Synopses. ${ }^{8}$ Here, the ready give-and-take language of the street, home, and shop was abundantly illustrated. The plays and movie synopses, when coupled with the viewing of the movies that they described, led to a knowledge of Japanese life.

Parallel with or following the Informal Conversations were The Geography of Japan, ${ }^{9}$ Military Conversations in Japanese, ${ }^{10}$ and Conversations in Japanese for Military Government Officers. ${ }^{11}$ 'The materials were technical, and the vocabulary was professional and

${ }^{8}$ Informal Conversations in Japanese, Including Plays and Movie Synopses (multigraphed edition), Japanese Language School, University of Michigan, Ann Arbor, 1945; part i, texts; part ii, vocabulary and grammar notes.

${ }^{9}$ The Geography of Japan (multigraphed edition), Japanese Language School, University of Michigan, Ann Arbor, 1944; part i, text; part ii, maps and word-lists.

${ }^{10}$ Military Conversations in Japanese (multigraphed edition), Japanese Language School, University of Michigan, Ann Arbor, 1945; part i, text; part ii, vocabulary.

${ }^{11}$ Conversations in Japanese for Military Government Officers (multigraphed edition), Japanese Language School, University of Michigan, Ann Arbor, 1945 ; part i, text; part ii, vocabulary and grammar notes. 
useful; the students at all times dealt with materials that would be important in their future work.

The procedure thus described provided something to talk about. It took into account the fact that nothing is so deadly as a series of so-called free conversation hours for which no preparation has been made. Invariably the conversation in such hours turns to such time-worn questions as "What is your home city? What do you find there? What are the names of the schools that you went to?" Such questioning and answering usually becomes inane and silly.

Before the end of the course, regardless of the amount of spoken language material covered by the students, a total of twenty-five or thirty hours was devoted to the study and use of a selection from the topographical sheets issued by the Imperial Japanese Land Survey. The purpose was to show the nature of some of the obstructions that might be met in the case of invasion. With the less proficient students the amount of work that could be done with these topographical sheets was necessarily limited. But with the best students, matters of tactical military content and matters of military government could be discussed. All students acquired a sound knowledge of the 120 or more symbols used on the sheets, and an equally sound knowledge of the Japanese words and characters which describe the symbols.

For the Speech Hours questions were prepared by the teachers or by the students, the students gave talks on subjects about which they had read, and debates and discussion groups were formed when controversial issues were raised. At all times failure to follow the forms of good usage led to correction by the teacher.

Once a week the Speech Hours were based on compositions written by the students. These compositions were used as guides in speech-making. At all times the emphasis was on the use of the vocabulary and grammar which had been learned by the student in connection with his oral work. Thus the compositions served as an additional check on the progress of the student.

Vocabulary lists as a basis for Speech Hours were of only limited use. Doi's Basic Japanese-English List ${ }^{12}$ is conveniently arranged 1935.

12 Found as a leaflet in K. Doi, Basic Japanese, Rokuseikwan, Tokyo, 
under various subject-headings, such as the human body, plants, animals, society, etc. Unfortunately the listings consist almost entirely of nouns, whereas the verbs and adjectives naturally used with these nouns are never given with them, so that rapid-fire questioningand-answering could not be carried on. An attempt to correct the shortcomings of the Doi list was made in compiling A Basic EnglishJapanese Vocabulary of Words Arranged According to Subjects. ${ }^{13}$ This vocabulary became the basis of $A$ Japanese Picture Dictionary, ${ }^{14}$ for which Dr. Joseph D. Sasaki, a member of the staff, drew 59 plates of pictures illustrating all sorts of words and actions. Special word-lists were compiled by the staff when the technical nature of some of the instruction in military and administrative affairs required them. ${ }^{15}$

Japanese films were shown on an average of almost once a week throughout the history of the Japanese School. Each film was shown at least three times. Insofar as possible, a synopsis in English was issued beforehand so that a reasonably clear idea of the characters and action might be had. At the showings, the students were seated with their instructors. During the first showing, breaks at the end

13 A Basic English-Japanese Vocabulary of Words Arranged According to Subjects (multigraphed edition), Japanese Language School, University of Michigan, Ann Arbor, 1945.

${ }_{14}$ Joseph D. Sasaki, A Japanese Picture Dictionary (multigraphed edition), Japanese Language School, University of Michigan, Ann Arbor, 1945; part i, pictures; part ii, vocabulary.

is The following word-lists were compiled by the staff of the Japanese Language School:

a. A Basic English-Japanese Military Vocabulary (multigraphed edition), 1945.

b. A Glossary of Censorskip and Communications Terms in Japanese (mimeographed edition), Ann Arbor, n. d.

c. An English-Japanese Glossary of Geographical Terms (multigraphed edition), 1944.

d. Terms for Japanese History (Japanese to English) (mimeographed edition), 1944.

e. A Place-name List for the Japanese Empire (multigraphed edition), 1944.

f. Vocabulary on Architecture (English to Japanese and Japanese to English) (multigraphed edition), n. d.

g. An English-Japanese Glossary of Industrial Terms (multigraphed edition), 1944.

h. Vocabulary on Communication (English to Japanese and Japanese to English) (multigraphed edition), $n$. d. 
of every two reels or so allowed the students to ask questions of their instructors. Even during the actual showing, questions could be asked. On the day following the first showing, students were given a true-false test on the factual details of the movie, and in discussion they were asked to describe the action. After the second showing the students were asked to talk on the nature of the characters, the social system depicted, etc. During the second and third showings, recordings were sometimes made of the more interesting scenes. The third discussion, after the third showing, often centered on these passages. Sometimes the discussion was devoted to the techniques employed in the making of Japanese films.

Lantern lectures were sometimes given in place of movies. In a typical lantern lecture hour, the lecturer gave three short lectures on different subjects. Each lecture was followed by a short true-false examination. The first lecture was given in very simple Japanese on a relatively simple subject. The second and third lectures were progressively more difficult both in language and in subject-matter. In this way students of varying proficiency could be accommodated, and instructors could find out the relative abilities of the students.

Speech contests were a valuable supplement in the advanced work. All students competed in the first contest, giving short extemporaneous talks. Winners were judged on the basis of pronunciation, content, sentence structure, and delivery. Two winners selected from each section competed against the other section winners. The final contest was made up of prepared speeches five minutes in length.

The impression created by the foregoing description of the spoken language program may be that it was unusually heavy, with the students exposed to a great quantity of material. However, as long as the reading lessons for the day were the basis for the Speech Hours, the students tried to increase their use of the vocabulary and grammar found in the reading lessons. By the end of the third term (after nine months) the best students were able to take fresh materials for the Speech Hours, and in the fourth term were able to take most of the new materials in kanzi and kana, that is, in characters instead of in romanization. The gradation was from simple to complex materials. The School relied to a great extent on multiple exposure. The program was aimed at more or less filling the stu- 
dents' ears with Japanese and hoping for a great increase in control. The opposite procedure would have been to limit the grammar and vocabulary. The School tended to favor the former procedure, partly because past attempts at compiling really serviceable word-lists have not been successful. They do not cover the greetings and preliminaries that start any conversation. The words listed are often given single translations covering perhaps the chief use and no more. Finally, no one can get along on the thousand or so words that are usually given. The School tried to teach its students a broad basic vocabulary. The words found in the elementary texts pertained to the body, dress, dwellings, food, drink, etc. Various cultural aspects of Japanese life were then taken up. Specialization in the fields of geography, the military, and civil administration followed. Since it was also necessary to teach grammar and to try to have the students arrive at the greatest possible flexibility in the use of grammar, our task was by no means easy. The number of permutations and combinations possible for the inflected forms of the language, not to mention the particles, is simply tremendous. To create acceptable habits of usage in these forms calls for the best teaching procedures.

The majority of students will never talk exactly like native speakers, but even a poor student can be taught to talk Japanese so that he may express not only his basic desires but gather information of importance. Though errors in pronunciation, grammar, or word usage should never be condoned, the drive toward fluency sometimes means that accuracy is made secondary. The teacher sometimes takes refuge in the thought that even a little knowledge of a foreign language may make it useful to an intelligent user. Fortunately, in the Army Japanese Language School, the students were of high intelligence. Much more can be done with such students than with the usual run of students. The best students finally began to talk with fluency and phonetic accuracy. 